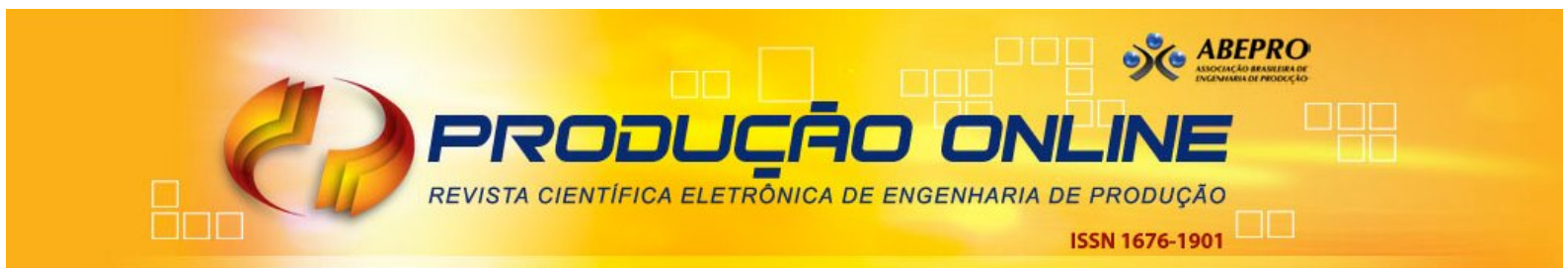

\title{
MODELAGEM E ANÁLISE DA CONFIABILIDADE DO PROCESSO DE TRANSFORMAÇÃO DE POLÍMEROS DE UMA UNIDADE DE PRODUÇÃO DE SANEANTES
}

\section{RELIABILITY MODELING AND ANALYSIS OF THE POLYMER TRANSFORMATION PROCESS OF A SANITISING INDUSTRY}

\author{
Murilo Leite Alcantara* Email: muriloleite.eq@gmail.com \\ Isabel Sartori ${ }^{\star \star}$ Email: sartori@ufba.br \\ Marcelo Embiruçu** Email: embirucu@ufba.br \\ *Programa de Engenharia Química, Universidade Federal da Bahia (UFBA), Salvador BA \\ **Programa de Engenharia Industrial, Universidade Federal da Bahia (UFBA), Salvador BA
}

\begin{abstract}
Resumo: Uma das etapas mais importantes para a maioria dos processos de produção de saneantes é a fabricação dos frascos (embalagens primárias) dos produtos, comumente realizada através de transformação de polímeros, tais como extrusão e sopro. Um crescimento na produção de forma segura requer o uso de meios para reduzir a ocorrência de falhas. O estudo sobre confiabilidade de sistemas de produção pode ser utilizado como uma ferramenta para compreender e prever o comportamento da confiabilidade das unidades industriais. $O$ presente trabalho estuda o comportamento da confiabilidade de uma unidade industrial de saneantes com foco na produção dos frascos. Os estudos feitos neste trabalho foram baseados em três métodos de modelagem: Global Life Distribution (GLD, distribuição de vida global), Composite Life Distribution (CDL, distribuição de vida composta) e Optimum Composite Life Distribution (OCDL, distribuição de vida composta ótima). As distribuições utilizadas neste trabalho foram: exponencial, Weibull, normal, lognormal, $q$-exponencial e $q$-Weibull. Os resultados obtidos pelos três métodos foram comparados com os dados experimentais. A metodologia OCLD herda as potencialidades, mas supera as limitações, de ambas as metodologias GLD e CLD, pois, além de representar bem o comportamento do sistema global, possibilita também uma representação dos subsistemas, ou modos de falha, que o compõem. Neste trabalho foi realizada uma análise da contribuição dos modos de falha para a probabilidade de falha do sistema global. O valor calculado para o lucro cessante demonstra a oportunidade de benefício financeiro que pode ser obtido com possíveis aprofundamentos e desdobramentos futuros do estudo realizado.
\end{abstract}

Palavras-chave: Confiabilidade. OCLD. Polímero. Extrusão. Moldagem por sopro.

Abstract: The sanitizing industry has had a growing importance in the Brazilian industrial sector. One of the most important steps for most of the sanitizing industries is the production processes of bottles. The production of these bottles is usually carried out through polymer processing methods such as extrusion and blow molding. In order to increase the industrial production safely, it is necessary to use methods to reduce the occurrence of failures. The study of production systems reliability can be used as a tool to understand and predict the behavior of industrial units' failures. This paper studies the reliability behavior of a sanitizing industry with the focus on the bottles production. This study was based on three modeling methodologies: Global Life Distribution (GLD), Composite Life Distribution (CDL) and Optimum Composite Life Distribution (OCDL). The distributions used were: exponential, Weibull, normal, lognormal, q-

Revista Produção Online, Florianópolis, SC, v.15, n. 1, p. 345-374, jan./mar. 2015. 
exponential and $q$ - Weibull. The reliability behaviors found by these three methodologies were compared with the reliability obtained experimentally. The OCLD methodology overcomes the limitations of both GLD and CLD methodologies, but inherits their strengths. The OCDL methodology resulted in a good representation of the subsystems as well as the overall system behavior. It is also carried out in this paper an analysis of the contribution of the subsystems to the overall probability of system failure. The outgoing profit was calculated and it is a potential indicative of financial benefit that can be obtained with possible future developments of the study.

Keywords: Reliability. OCLD. Polymer. Extrusion. Blow molding.

\section{INTRODUÇÃO}

O presente trabalho visa estudar o comportamento da confiabilidade de uma unidade industrial de produtos de limpeza (saneantes), importante setor industrial brasileiro, tanto do ponto de vista econômico quanto de saúde pública.

O elevado número de doenças originadas da falta de higiene é um dos responsáveis pela crescente utilização de meios preventivos como os saneantes. As vendas mundiais de produtos de limpeza em 2010 foram de aproximadamente US\$ 148,9 bilhões (EUROMONITOR, 2011) e o Brasil contribuiu com 6,2\% dessas vendas (ABIPLA, 2011). No grupo dos BRIC (Brasil, Rússia, Índia e China), o Brasil se destaca com 32\% da participação em 2010, atrás apenas da China. O mercado brasileiro dos produtos de limpeza, que era de $R \$ 9$ bilhões em 2003, registrou cerca de $R \$ 13,5$ bilhões no ano de 2010 (ABIPLA, 2011), com o setor crescendo mais do que o PIB brasileiro (IBGE, 2011). Aumentar a produtividade pode aumentar os riscos na produção, já que, em geral, para aumentar a produtividade sem aumentar os riscos é necessário um processo com altos níveis de confiabilidade (SARTORI, 2012). As técnicas e estudos sobre confiabilidade são utilizados como uma ferramenta para a tomada de decisões de gestão, fornecendo informações que auxiliam na implementação de políticas que minimizem os custos e riscos envolvidos nos processos de produção.

O problema aqui investigado insere-se no contexto de uma indústria de pequeno/médio porte que produz saneantes domissanitários e o foco do trabalho é a modelagem das falhas das máquinas (dos tipos sopradora e extrusora/sopradora) de transformação de polímeros que são utilizadas na produção das embalagens primárias Revista Produção Online, Florianópolis, SC, v.15, n. 1, p. 345-374, jan./mar. 2015. 
(comumente chamadas de frascos), utilizadas no envase do saneante. Alguns estudos recentes sobre confiabilidade têm sido feitos com o foco na extrusão de diversos tipos de produtos. A maioria deles, no entanto, estuda o comportamento de produtos ou instrumentos de um processo (SHEIKH et al., 2004; YOUNAS et al., 2008; SALEM e SENE, 2011), e poucos trabalhos focam-se no processo de produção propriamente dito. Além disto, a maioria destes estudos arbitra uma distribuição, usualmente a Weibull (YOUNAS et al., 2008; SALEM e SENE, 2011, MENGUE e SELLITTO, 2013), como modelo para representar a confiabilidade, estimando seus parâmetros para ajustá-la aos dados do sistema. Uma abordagem mais completa consiste no ajuste de diversas distribuições, usualmente apenas as clássicas (p.e.: SHEIKH et al., 2004; CROOKSTON et al., 2011, LOPES e SAMOHYL, 2003), aos dados do sistema global seguido pela seleção daquela que melhor representa o comportamento da confiabilidade do sistema. Rausand (2004) e Birolini (1999) modelam a confiabilidade de sistemas através da composição da confiabilidade dos subsistemas. Sartori (2012) otimizou este método de composição dos subsistemas através de re-estimativas dos parâmetros.

O objetivo deste trabalho é estudar o comportamento da confiabilidade dos processos de extrusão e sopro de uma unidade industrial transformadora de polímeros, aplicando novas metodologias de estimativa de confiabilidade de sistemas. Para a modelagem das falhas, o presente estudo avalia, além das distribuições de vida clássicas, a utilização de duas distribuições generalizadas que foram recentemente aplicadas à área de confiabilidade: a q-exponencial e a $q$-Weibull. A metodologia de composição ótima da confiabilidade proposta por Sartori (2012) foi aplicada na determinação da confiabilidade de cada máquina transformadora. O modelo gerado a partir desta metodologia, chamado de distribuição de vida composta ótima (OCLD, Optimum Composite Life Distribution), foi comparado com outros métodos de determinação da confiabilidade de sistemas. Além disso, foi realizada também uma análise da contribuição dos modos de falha para a probabilidade de falha do sistema global.

Revista Produção Online, Florianópolis, SC, v.15, n. 1, p. 345-374, jan./mar. 2015. 


\section{DESCRITIVO DO PROCESSO}

A linha de produção da unidade industrial estudada trabalha com oito tipos de produtos em sua linha de produção: água sanitária; alvejante; detergente; lava-louça; amaciante; desinfetante; multiuso; e sabão-gel. A empresa utiliza um processo de produção que consiste simplificadamente em quatro etapas, como pode ser observado na Figura 1: produção de frascos (embalagens primárias); formulação dos saneantes; envase; e estocagem.

Figura 1 - Fluxograma simplificado de produção dos saneantes

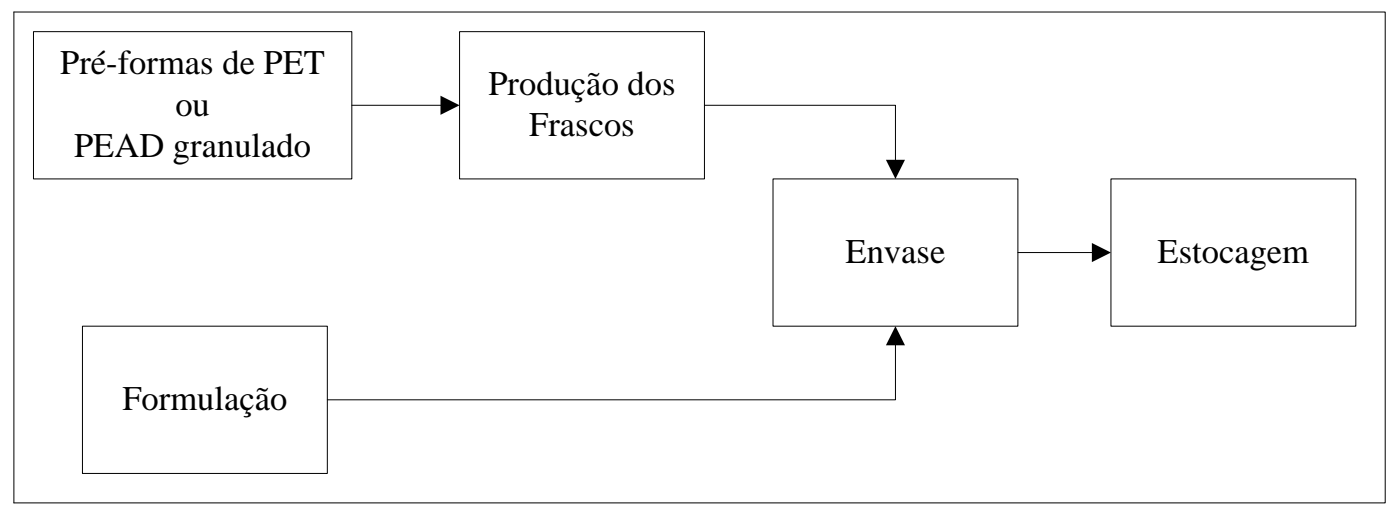

Fonte: Alcântara (2013)

Devido à maior importância atribuída pelos responsáveis da planta em estudo, este trabalho tem como foco o processo de produção dos frascos. Este processo possui cinco máquinas de transformação de polímeros. A máquina 1 utiliza pré-formas de poli(tereftalato de etileno) [PET, Poly(Ethylene Terephthalate)] e o seu processo de fabricação consiste simplificadamente nos processos de pré-aquecimento e sopro. As quatro máquinas restantes (máquinas 2, 3, 4 e 5) são do tipo extrusora/sopradora, e utilizam como matéria-prima PEAD (PoliEtileno de Alta Densidade) granulado. Estas quatro máquinas são do mesmo fabricante e se diferenciam principalmente devido ao modelo do equipamento. O modelo das máquinas 2 e 3 produz embalagens com alça e as máquinas 4 e 5 são de outro modelo, que produz embalagens sem alça. Durante o processo de produção das embalagens, diversas operações unitárias são utilizadas, Revista Produção Online, Florianópolis, SC, v.15, n. 1, p. 345-374, jan./mar. 2015. 
tais como: turbo-aspiração; vasos e tanques; filtragem; transporte por rosca sem fim; fusão de sólidos; filtragem; extrusão e operação com tréfila e mandril; moldagem; corte com facas.

\section{MATERIAIS E MÉTODOS}

\subsection{Análise dos Modos de Falha e Lucro Cessante}

Para a realização do presente estudo, foram utilizados os dados operacionais de um período de oito meses. Em uma rotina normal de trabalho, a unidade industrial em estudo funciona de segunda a sexta e, nestes dias, toda a produção de embalagens é parada das cinco horas da tarde às sete horas da manhã do dia seguinte e no intervalo de meio dia até uma hora da tarde (horário de almoço), totalizando nove horas diárias de produção. As considerações feitas na geração do banco de dados de confiabilidade a partir dos dados brutos fornecidos pela empresa estão detalhadas em Alcântara (2013), sendo que as principais foram:

(a) só foram consideradas as paradas ocasionadas por falha de algum componente do sistema. Alguns motivos de parada não foram considerados, tais como manutenção planejada, limpeza e inspeção, falta de programação (quando não é viável a produção ou não tem espaço para estocagem do produto), falta de matéria prima (pré-formas de PET ou PEAD), troca da matéria prima, indisponibilidade dos operadores (devido a reuniões, treinamentos, almoços e recessos), indisponibilidade da rotuladora (por estar sendo utilizada por outra máquina, por falta de rótulos ou por falha), realização de testes e aquecimento das zonas térmicas;

(b) devido ao baixo índice de falha dos demais processos envolvidos na produção da linha de produção, foi considerado que suas confiabilidades são de 100\%;

(c) não foram consideradas falhas ocorridas durante as manutenções.

Os dados fornecidos pela empresa possuem 64 diferentes tipos de modos de falhas. As falhas foram classificadas em cinco grupos. Quatro destes grupos equivalem aos modos de falha que apresentam maior frequência ou que resultam em maior tempo de parada da planta. O quinto grupo consiste nos demais modos de falha que possuem 
frequência de ocorrência muito baixa (menor do que 1\%) e nas paradas para as quais não foram identificados os modos de falha. Conforme explicado anteriormente no descritivo de processo, a máquina 1 utiliza pré-formas de $\mathrm{PET}$, não possuindo a etapa de extrusão e, desta forma, não apresenta os modos de falha no filtro nem na faca de corte. O Quadro 1 descreve as falhas pertinentes a cada modo de falha.

Quadro 1 - Modos de falha da produção dos frascos

\begin{tabular}{|c|c|}
\hline Modos de Falha & Descrição \\
\hline Falha no molde & $\begin{array}{l}\text { São falhas no molde que ocasionaram parada por motivos tais como } \\
\text { isolamento das cavidades; vazamento de água no molde; ajustes no molde } \\
\text { troca dos moldes; troca dos anéis dos moldes. }\end{array}$ \\
\hline Falha no filtro & $\begin{array}{l}\text { São falhas no filtro que ocasionaram parada por motivos tais como: troca da } \\
\text { tela; troca do filtro; limpeza do filtro. }\end{array}$ \\
\hline $\begin{array}{l}\text { Falha na faca de } \\
\text { corte }\end{array}$ & $\begin{array}{l}\text { Dentro deste grupo estão incluídos: falha na bucha de corte; falha no cabo da } \\
\text { faca; falha ou troca da faca; ajuste dos cortes; troca dos anéis de corte. }\end{array}$ \\
\hline Falha na tréfila & $\begin{array}{l}\text { Dentro deste grupo estão incluídas: troca da tréfila; manutenção da tréfila; } \\
\text { limpeza da tréfila. }\end{array}$ \\
\hline $\begin{array}{c}\text { Falhas não } \\
\text { determinadas ou } \\
\text { esporádicas }\end{array}$ & $\begin{array}{l}\text { Neste grupo estão incluídas as paradas relativas às falhas sem informação } \\
\text { explícita do motivo da falha, os motivos de falha que resultaram em menos de } \\
\text { um por cento do tempo total de produção ou com frequência de incidência } \\
\text { menor ou igual a três vezes ao mês, tais como: problemas na torre de } \\
\text { resfriamento; vazamento de ar ou água (com exceção de vazamentos no } \\
\text { molde); troca de óleo; falha no mandril; limpeza da cabeça da máquina; falha } \\
\text { na vareta do sopro; falha no sistema de ar comprimido; lâmpada queimada } \\
\text { falha no extrator; falha na mangueira; falha elétrica; quebra de parafusos; falha } \\
\text { na bobina; falha no cabo da resistência; falha na válvula; falha na rosca. }\end{array}$ \\
\hline
\end{tabular}

Fonte: Próprio autor

A análise da contribuição dos modos de falha pode ser utilizada, dentre outros motivos, como forma de avaliar a influência de cada modo na probabilidade de falha do sistema global. Para tanto, a contribuição relativa de cada subsistema, para a falha das máquinas, foi quantificada de forma análoga à realizada por Castet e Saleh (2009).

Conforme ressaltado por Sartori (2012), os estudos sobre confiabilidade são instrumentos importantes na implementação de políticas que minimizem os custos e reduzam o lucro cessante anual referente às paradas da planta ocasionadas por falhas.

Revista Produção Online, Florianópolis, SC, v.15, n. 1, p. 345-374, jan./mar. 2015. 
Neste sentido, foram calculados os tempos indisponíveis ocasionados pelas falhas das máquinas individualmente, a produção horária de frascos, a produção cessante devido às paradas ocasionadas por falhas, o lucro por embalagem e o lucro cessante de cada máquina. Após este levantamento, foi estimado ainda o lucro cessante total $(O P$, Outgoing Profit) através da equação (1).

$$
O P=\frac{t_{d}}{t_{p o}} \cdot P S P \cdot P
$$

onde $t_{d}$ é o tempo indisponível devido às falhas, $t_{p o}$ é o tempo planejado para a operação, PSP é o preço de venda do produto (Product Sales Price) e $P$ é a produção total. O preço de venda do produto foi substituído pelo lucro líquido unitário, com a finalidade de se obter resultados mais representativos. A produção total foi estimada através da capacidade de produção de cada máquina e do tempo total de operação.

\subsection{Abordagens de Modelagem}

Uma das formas mais simples de modelar a confiabilidade de um sistema consiste em selecionar arbitrariamente uma distribuição para representar os dados. Este método envolve várias considerações e pode não representar bem o comportamento da confiabilidade do sistema. Segundo Sartori (2012), este é um dos métodos mais utilizados atualmente na prática, devido à sua simplicidade. Aqueles que optam por esta metodologia costumam ter maior preferência pela distribuição exponencial. Esta distribuição possui taxa de falha constante, o que resulta em expressões mais simples para análises de confiabilidade.

No presente trabalho são analisadas diversas distribuições para selecionar as expressões que melhor ajustam a confiabilidade de cada sistema, além de algumas distribuições clássicas, tais como: exponencial; Weibull; normal; e lognormal. Distribuições generalizadas, das quais as distribuições clássicas são um caso especial, são uma possibilidade quando se deseja empregar distribuições mais complexas. Revista Produção Online, Florianópolis, SC, v.15, n. 1, p. 345-374, jan./mar. 2015. 
Distribuições estatísticas generalizadas recentemente desenvolvidas no âmbito da mecânica estatística não-extensiva, proposta por Tsallis (1988), são conhecidas como $q$-distribuições. Assim, no contexto deste trabalho também serão utilizadas $q$ distribuições: $q$-exponencial; e $q$-Weibull. Segundo Nadarajah e Kotz (2007), as $q$ distribuições foram encontradas em vários fenômenos físicos e sociais e em sistemas complexos artificiais. Segundo Picoli et al. (2009), elas geralmente resultam em melhores ajustes de sistemas complexos em comparação às distribuições clássicas.

As diversas distribuições analisadas serão tratadas através de três diferentes métodos de modelagem de dados. Na Global Life Distribution (GLD, distribuição de vida global), a modelagem é relativamente simples. Ela consiste basicamente no ajuste das distribuições a todos os dados disponíveis. Isto é feito com o objetivo de encontrar os parâmetros que melhor representam a confiabilidade do sistema e, com o resultado do ajuste das diferentes distribuições, selecionar aquela que obteve a melhor representatividade dos dados. Como mostrado na literatura (BIROLINI, 1999; RAUSAND, 2004; SARTORI, 2012), a confiabilidade de sistemas pode ser determinada através da composição da confiabilidade dos seus subsistemas, a chamada Composite Life Distribution (CLD, distribuição de vida composta). Neste método, os dados são divididos em subsistemas para que seja possível realizar ajustes das confiabilidades individuais de cada um deles. A partir das expressões de confiabilidade de cada subsistema, faz-se uma composição destas a fim de encontrar uma expressão capaz de representar o sistema global. Este método de modelagem representa bem os subsistemas, mas pode não ser o melhor para representar os dados do sistema global. Sartori (2012) propõe um método alternativo para melhorar os resultados obtidos através da CLD, conhecido como Optimum Composite Life Distribution (OCLD, distribuição de vida composta ótima). Este método consiste basicamente na otimização dos parâmetros obtidos pela metodologia da CLD. Através de re-estimativas de parâmetros, esta modelagem ajusta a expressão composta aos dados do sistema global, resultando em uma melhor representatividade do comportamento da confiabilidade dos dados do sistema global. 


\section{RESULTADOS E DISCUSSÃO}

\subsection{Análise dos Modos de Falha e Lucro Cessante}

A Figura 2 (a) mostra o tempo máximo de operação (TMO) e suas divisões. Uma parcela em torno de treze por cento deste tempo é referente a manutenções corretivas ocasionadas por falhas não previstas, e a Figura 2 (b) apresenta a análise da distribuição destas falhas segundo os grupos aos quais elas pertencem. É importante ressaltar que os modos de falha relativos ao filtro, à tréfila e à faca de corte não resultaram em grandes períodos de tempo de parada da fábrica, fato que poderia justificar sua inclusão no grupo de falhas não determinadas ou esporádicas. Entretanto, estes modos de falha apresentam altos índices de ocorrência em algumas máquinas e, por isso, foram classificados como modos de falha específicos estudados no presente trabalho.

Dentro da parcela do TMO referente às falhas, o grupo das falhas não determinadas ou esporádicas se destaca, com aproximadamente metade do valor total. Este alto valor pode ser justificado pela grande quantidade de falhas com baixa frequência. Segundo o critério de seleção mostrado no Quadro 1, as falhas com incidência menor do que um por cento ou com incidência menor ou igual a três vezes por mês são classificadas dentro do grupo de falhas não determinadas ou esporádicas. 
Figura 2 - Análise das falhas: (a) análise do tempo máximo de operação (TMO); (b) análise do tempo indisponível ocasionado por falha

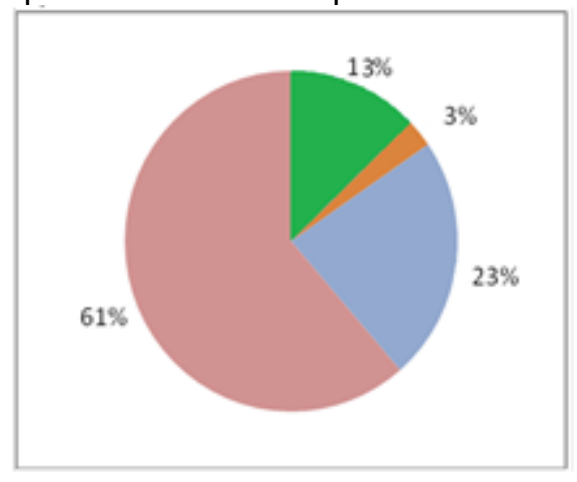

- Tempo indisponivel ocasionado por falha

= Manutenção Planejada

= Paradas não ocasionadas por faltha

= Tempo de operação efetiva (a)

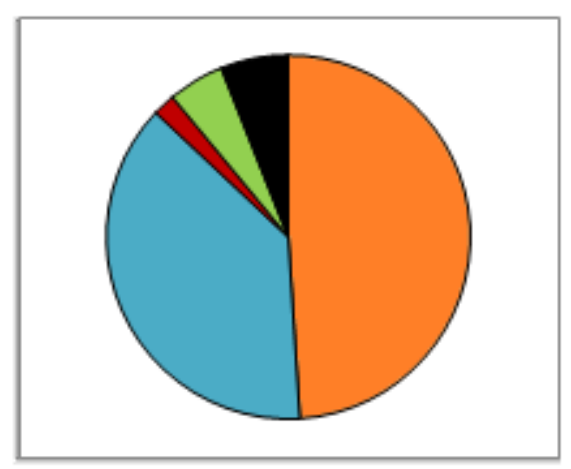

(b)
Falha no Molde

- Falha no Filtro

- Falha na Faca de corte

- Falha na Tréfila

- Falhas não determinadas ou esporádicas

Fonte: Próprio autor

Como a fábrica está ativa durante nove horas por dia, e apenas de segunda a sexta, o seu TMO semanal é de quarenta e cinco horas, resultando em um TMO anual de aproximadamente duas mil e trezentas horas. Como observado anteriormente, o tempo indisponível ocasionado por falhas é de aproximadamente treze por cento, ou aproximadamente trezentas horas anuais de máquinas paradas.

Em relação ao tempo indisponível ocasionado pelas falhas das máquinas individualmente, a Tabela 1 mostra um detalhamento da produção horária de frascos, da produção cessante devido às paradas ocasionadas por falhas e do lucro cessante de cada máquina. Somando os montantes de todas as máquinas chega-se a um valor aproximado de $\mathrm{R} \$ 215.600,00$ de lucro cessante provocado pelas paradas das 
máquinas devido às falhas, o que mostra a importância econômica do estudo de confiabilidade.

Tabela 1 - Tempo indisponível e lucro cessante ocasionados por falhas para cada máquina

\begin{tabular}{cccccc}
\hline $\begin{array}{c}\text { Máquina } \\
\text { (M) }\end{array}$ & $\begin{array}{c}\text { Tempo de } \\
\text { parada (\%) }\end{array}$ & $\begin{array}{c}\text { Tempo de } \\
\text { parada anual (h) }\end{array}$ & $\begin{array}{c}\text { Produção } \\
\text { (frascos/hora) }\end{array}$ & $\begin{array}{c}\text { Produção } \\
\text { cessante de } \\
\text { frascos }\end{array}$ & $\begin{array}{c}\text { Lucro } \\
\text { cessante } \\
\text { (R\$) }\end{array}$ \\
\hline 1 & 27,36 & 82,08 & 680 & 55.817 & 18.350 \\
2 & 10,71 & 32,13 & 750 & 24.094 & 31.856 \\
3 & 22,10 & 66,30 & 570 & 37.791 & 105.250 \\
4 & 32,25 & 96,75 & 100 & 9.675 & 11.299 \\
5 & 7,58 & 22,74 & 1.720 & 39.117 & 48.867 \\
\hline
\end{tabular}

Fonte: Próprio autor

Uma vez determinada a importância econômica, o estudo da contribuição para a probabilidade de falha fornece informações mais específicas sobre os modos de falha predominantes no sistema, possibilitando uma tomada de decisão específica. As Figuras 3 a 7 representam a contribuição relativa dos subsistemas (modos de falha) para as falhas das máquinas, de acordo com os tempos de falha.

Em relação à máquina 1 (Figura 3), observa-se a presença de apenas dois modos de falha. Os modos de falha na faca e no filtro não ocorrem nesta máquina devido à inexistência da etapa de extrusão, conforme explicado anteriormente na metodologia. O modo de falha na tréfila resultou em um baixo índice de ocorrência e foi adicionado às falhas não determinadas ou esporádicas. Para todos os intervalos de tempos de falha, o modo de falha no molde é o único que possui contribuição significativa, ressaltando a importância de uma maior atenção para este tipo de falha. 
Figura 3 - Contribuição dos modos de falha da máquina 1

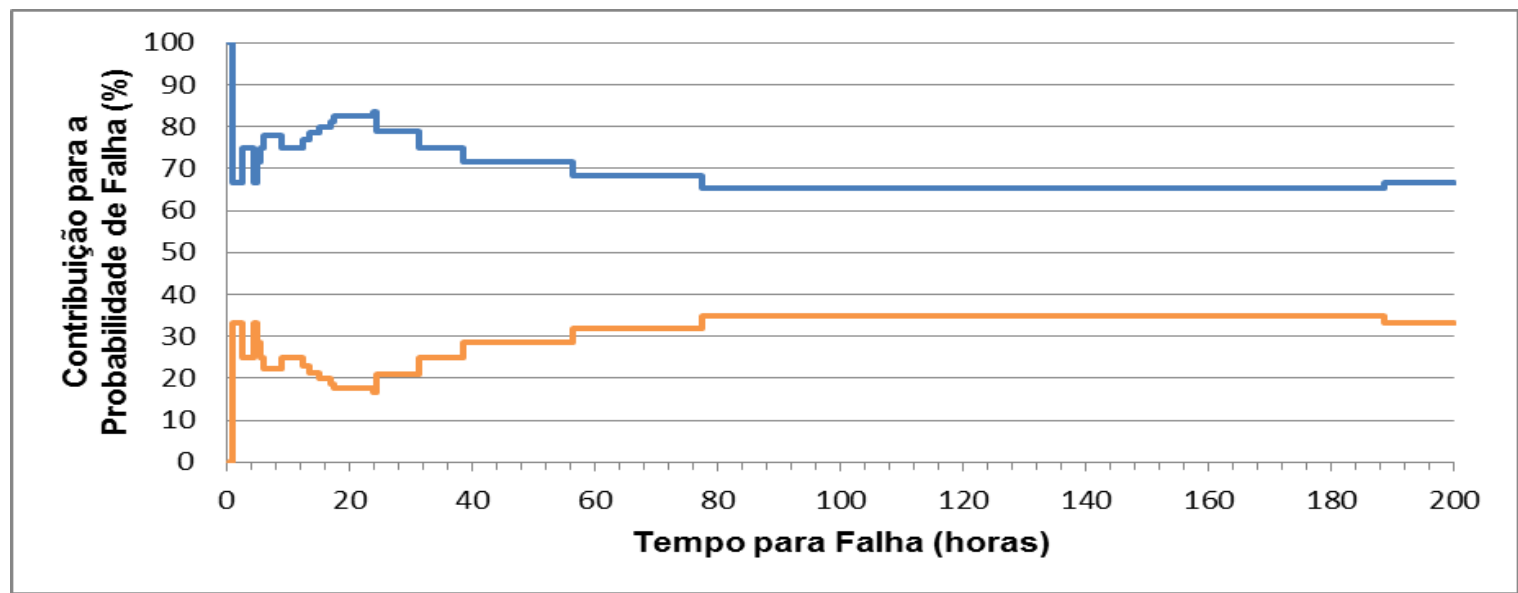

—Falha no Molde — Falha não Determinada

Fonte: Próprio autor

Para as máquinas 2 (Figura 4) e 3 (Figura 5), o modo de falha no molde foi o que apresentou o maior percentual de contribuição para tempos de falha pequenos, contribuição esta que decresce para tempos de falha maiores. No entanto, apesar das máquinas serem do mesmo modelo, o decréscimo no comportamento da contribuição é bem mais acentuado na máquina 2 do que na máquina 3 , sendo que a partir de tempos de falha maiores do que aproximadamente quatro horas a contribuição deste modo de falha para a máquina 2 chega a ser superada pela contribuição do modo de falha no filtro.

Ainda para as máquinas 2 e 3, foi verificado que as falhas na tréfila e na faca resultaram em uma contribuição menor. Essas contribuições representam um máximo de aproximadamente vinte por cento na máquina 2 e dez por cento na máquina 3 , sendo que, para a máquina 3 , a contribuição das falhas na tréfila foi tão pequena que elas foram incorporadas às falhas não determinadas. 
Figura 4 - Contribuição dos modos de falha da máquina 2

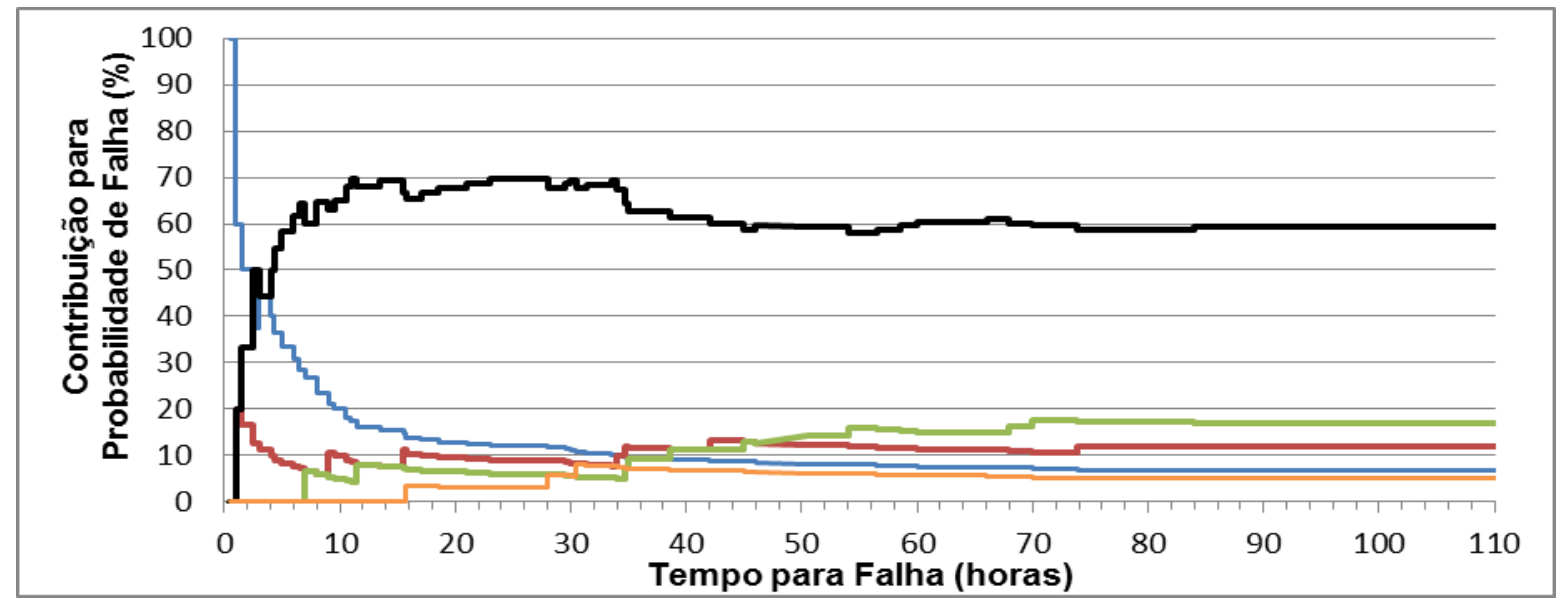

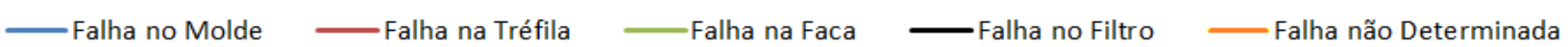

Fonte: Próprio autor

Figura 5 - Contribuição dos modos de falha da máquina 3

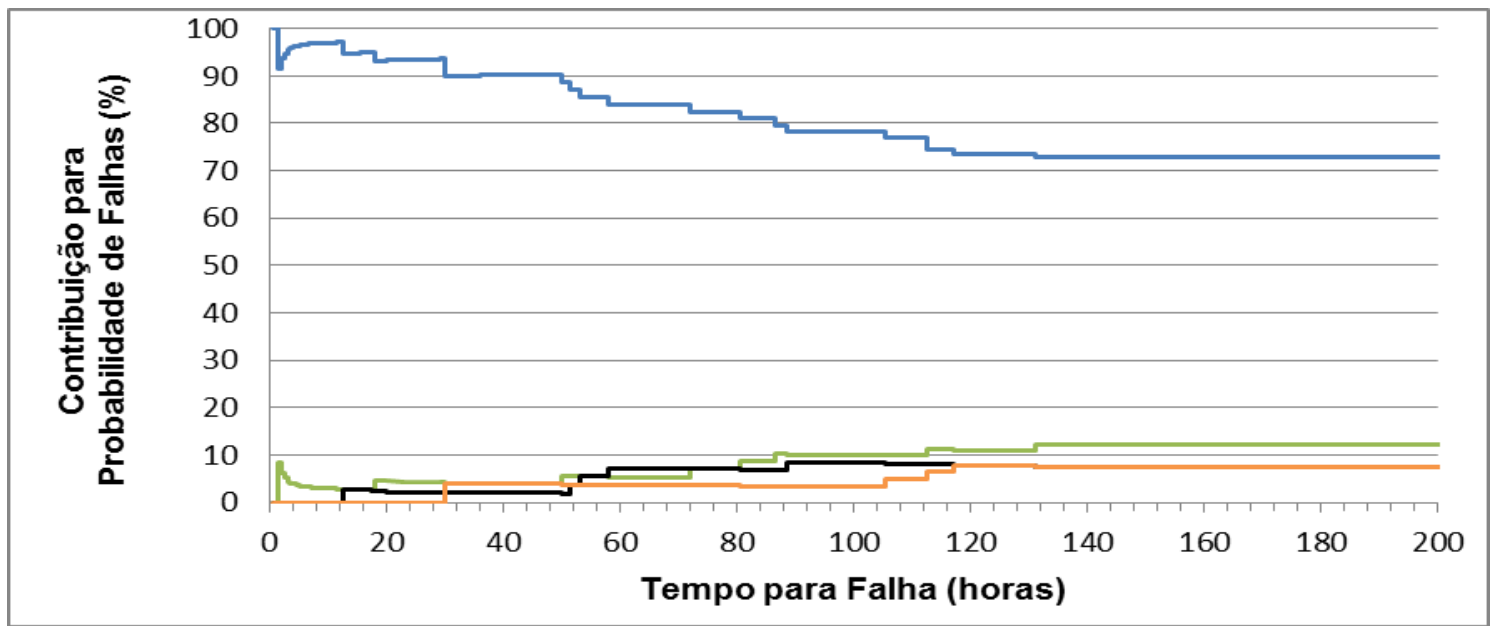

-Falha no Molde

-Falha na Faca

-Falha no Filtro

Falha não de terminada

Fonte: Próprio autor

As Figuras 6 e 7 representam a análise da contribuição de falhas das máquinas 4 e 5. Como pode ser observado, ambas resultaram em uma configuração semelhante, o que pode ser explicado devido ao fato destas máquinas serem do mesmo modelo. Apesar do subsistema de falhas não determinadas ter resultado em uma elevada Revista Produção Online, Florianópolis, SC, v.15, n. 1, p. 345-374, jan./mar. 2015. 
contribuição para estas máquinas, como previamente explicado, este subsistema agrega todos os modos de falha que não apresentaram quantidades de falhas significativas (maior do que um por cento das falhas do sistema global). Desta forma, as falhas no molde, na faca e na tréfila foram incorporadas a este subsistema, não tendo contribuição individual significativa. O único subsistema que possui contribuição individual significativa para o período estudado é o modo de falha no filtro, chegando a mais de vinte por cento para a máquina 4 e mais de trinta por cento para a máquina 5 .

Figura 6 - Contribuição dos modos de falha da máquina 4

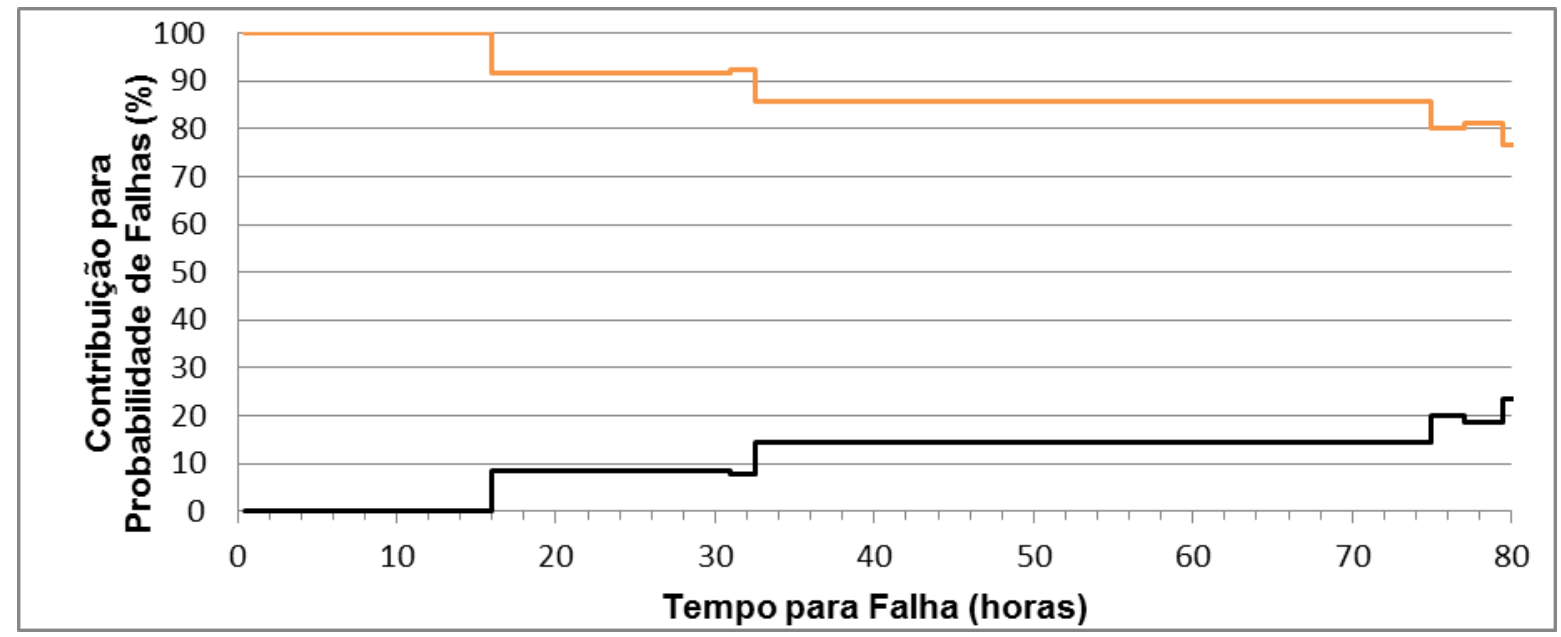

Falha no Filtro

Falha não determinada

Fonte: Próprio autor

Revista Produção Online, Florianópolis, SC, v.15, n. 1, p. 345-374, jan./mar. 2015. 
Figura 7 - Contribuição dos modos de falha da máquina 5

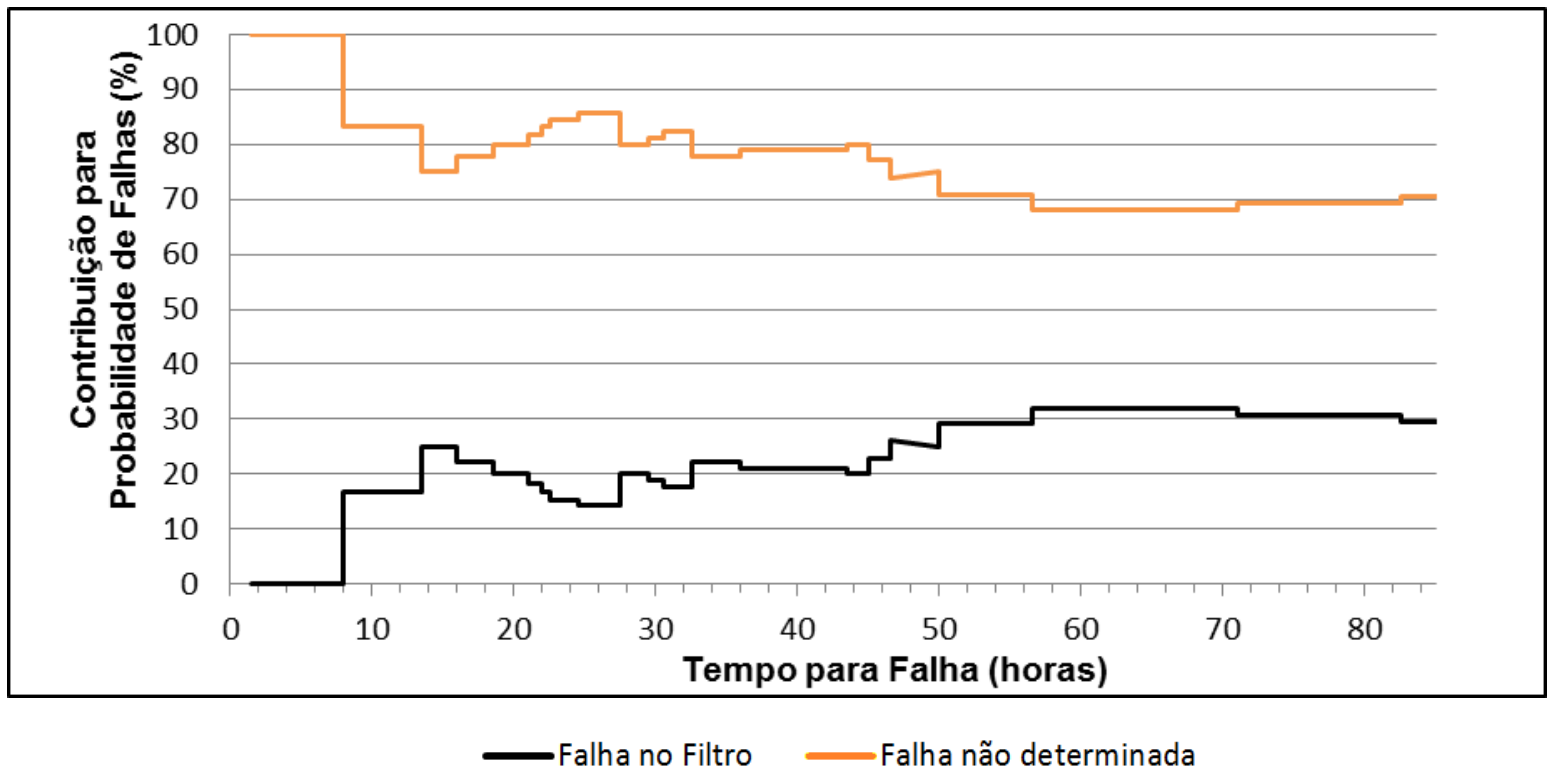

Fonte: Próprio autor

\subsection{Abordagens de Modelagem}

\subsubsection{Ajuste Segundo a Distribuição de Vida Global (GLD)}

Como descrito anteriormente, a distribuição de vida global (GLD) utiliza todos os dados de falha, independentemente do modo de falha. Todas as cinco máquinas foram modeladas através da abordagem GLD.

Para a determinação da distribuição que melhor represente a confiabilidade das máquinas, foram feitos ajustes dos dados com as distribuições exponencial, $q$ exponencial, Weibull, $q$-Weibull, normal e lognormal, cujas expressões das respectivas confiabilidades podem ser encontradas em outras referências (p.e., SARTORI, 2012). A probabilidade de falhas $(P)$ foi estimada através da aproximação medianranks, também conhecida como aproximação de Benard, segundo a definição proposta por Johnson (1950):

Revista Produção Online, Florianópolis, SC, v.15, n. 1, p. 345-374, jan./mar. 2015. 
$P(i)=\frac{i-0.3}{n+0.4}$

onde $n$ é o tamanho da amostra e $i$ é o número de ordenamento quando os tempos de falha são ordenados de forma crescente.

Os parâmetros das distribuições foram estimados utilizando o coeficiente de determinação $\left(R^{2}\right)$ como critério de ajuste. As distribuições, e seus respectivos parâmetros, que melhor se ajustaram aos dados das diferentes máquinas são apresentadas na Tabela 2 e na Figura 8, que compara os ajustes com os dados experimentais de planta.

Tabela 2 - Melhores distribuições para a GLD das cinco máquinas

\begin{tabular}{cccccccc}
\hline $\begin{array}{c}\text { Máquina } \\
(\mathbf{M})\end{array}$ & Distribuições & $\begin{array}{c}\text { Parâmetro } \\
\text { de forma } \\
(\boldsymbol{\beta})\end{array}$ & $\begin{array}{c}\text { Parâmetro } \\
\text { de escala } \\
(\boldsymbol{\eta})\end{array}$ & $\begin{array}{c}\text { Desvio } \\
\text { padrão } \\
(\boldsymbol{\sigma})\end{array}$ & $\begin{array}{c}\text { Média } \\
(\boldsymbol{\mu})\end{array}$ & $\begin{array}{c}\text { Parâmetro } \\
\text { "q" }\end{array}$ & $\begin{array}{c}\text { Coeficiente de } \\
\text { determinação } \\
\left(\mathbf{R}^{2}\right)\end{array}$ \\
\hline 1 & $q$-Weibull & 1,0555 & 7,5924 & - & - & 1,3700 & 0,99387 \\
2 & Lognormal & - & - & 1,5891 & 1,8887 & - & 0,99529 \\
3 & Lognormal & - & - & 1,4202 & 1,5379 & - & 0,99520 \\
4 & $q$-Weibull & 1,5176 & 1,6064 & - & - & 1,7264 & 0,98242 \\
5 & Weibull & 1,0667 & 31,752 & - & - & - & 0,98584 \\
\hline
\end{tabular}

Fonte: Próprio autor

Revista Produção Online, Florianópolis, SC, v.15, n. 1, p. 345-374, jan./mar. 2015. 
Figura 8 - Ajuste das distribuições propostas pela GLD par cada equipamento: (a) máquina 1;(b) máquina 2; (c) máquina 3; (d) máquina 4; (e) máquina 5

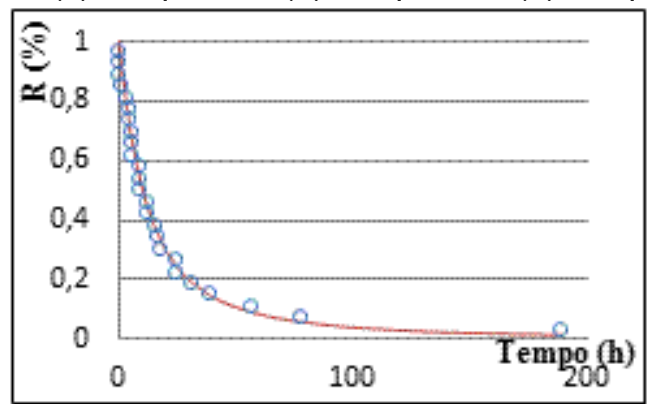

(a)

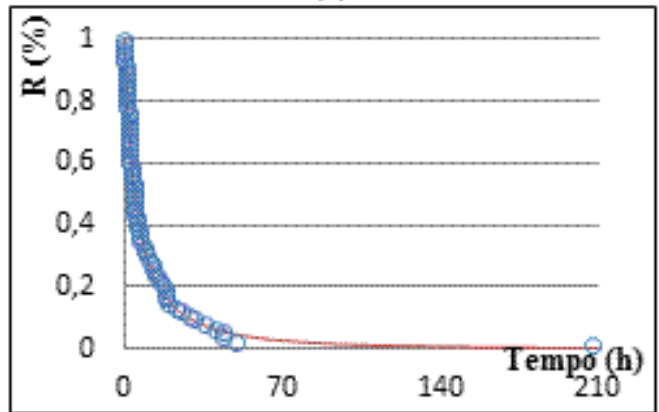

(c)

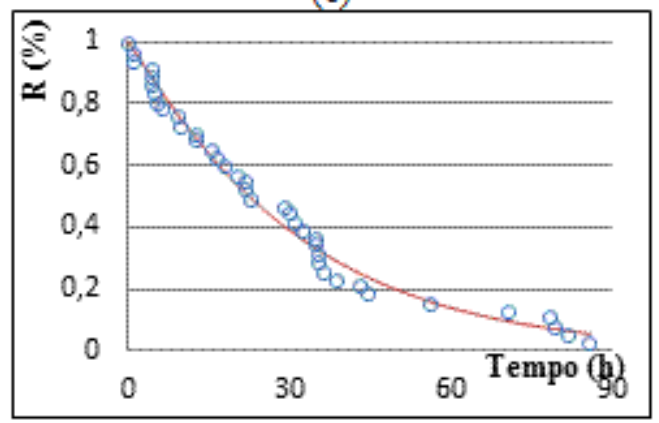

(e)

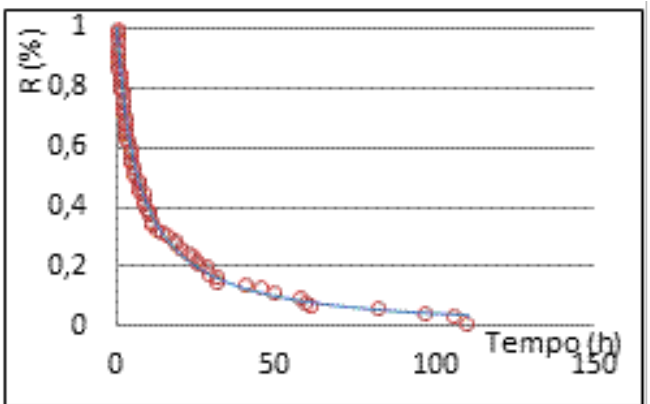

(b)

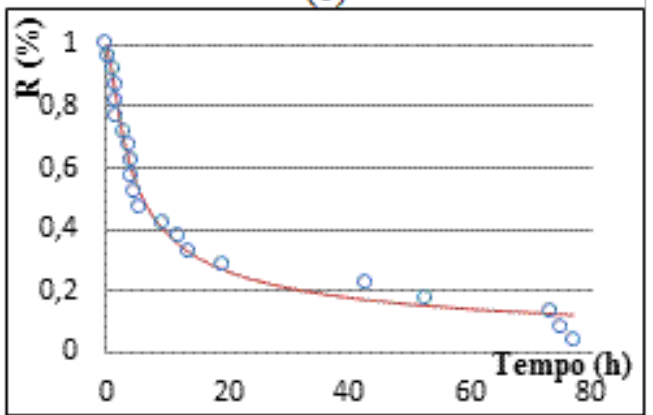

(d)

\section{Fonte: Próprio autor}

As expressões do comportamento da confiabilidade estimadas segundo a metodologia GLD resultaram em bons ajustes para os dados de falha das máquinas, como pode ser verificado pelos coeficientes de determinação acima de 0,98. Esta metodologia conseguiu resultados ainda melhores para as máquinas 1, 2 e 3, para as quais foram obtidos coeficientes de determinação acima de 0,99.

Revista Produção Online, Florianópolis, SC, v.15, n. 1, p. 345-374, jan./mar. 2015. 


\subsubsection{Ajuste Segundo a Distribuição de Vida Composta (CLD)}

Nesta abordagem os modelos da confiabilidade das máquinas são obtidos através da composição das distribuições dos dados de falha de cada subsistema. Como todos os subsistemas estão em série para os cinco equipamentos (Figura 9), a composição é o resultado da multiplicação da confiabilidade de cada subsistema.

Figura 9 - Diagrama de blocos para a modelagem CLD

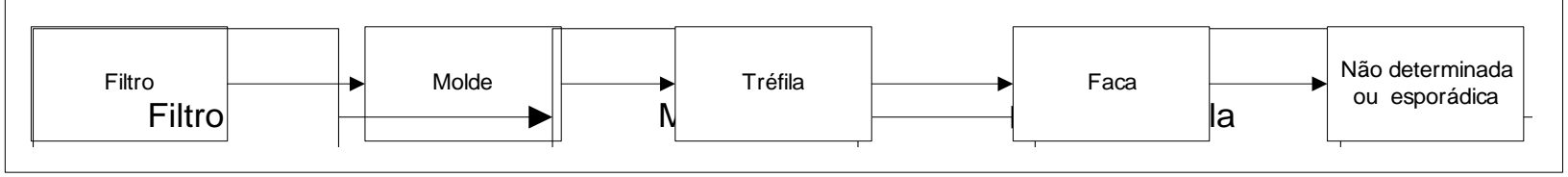

Fonte: Próprio autor

De modo semelhante à abordagem anterior, foram feitos ajustes de todas as distribuições e foi escolhida aquela que melhor representa o sistema. Na modelagem CLD estes ajustes são feitos individualmente para cada subsistema, aplicando o método GLD cinco vezes, uma para cada subsistema. Os melhores ajustes podem ser observados na Tabela 3, mostrados também na Figura 10, juntamente com os dados reais. Devido à pequena importância de alguns modos de falha para as demais máquinas, 1, 3, 4 e 5, uma abordagem mais simplificada foi adotada para elas. Os modos de falha com índice de ocorrência menor ou igual a três eventos foram considerados como falhas não determinadas ou esporádicas. Desta forma, a modelagem CLD das máquinas 4 e 5 foi feita apenas com os subsistemas falha no filtro e falhas não determinadas ou esporádicas. Na máquina 1 foram considerados apenas os subsistemas falha no molde e falhas não determinadas ou esporádicas, e o subsistema falha na tréfila não foi considerado na modelagem CLD da máquina 3. 
Tabela 3 - Ajuste das distribuições dos subsistemas das máquinas (M) 1, 2, 3 , 4 e 5

\begin{tabular}{|c|c|c|c|c|c|c|c|c|}
\hline $\begin{array}{l}\text { Modo de } \\
\text { Falha }\end{array}$ & Distribuição & $\begin{array}{l}\text { Parâmetro } \\
\text { de forma } \\
(\beta)\end{array}$ & 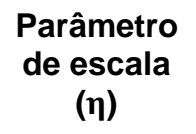 & $\begin{array}{l}\text { Desvio } \\
\text { padrão } \\
(\sigma)\end{array}$ & $\begin{array}{l}\text { Média } \\
(\mu)\end{array}$ & $\begin{array}{l}\text { Parâmetro } \\
\text { "q" }\end{array}$ & $\mathbf{R}^{2}$ & M \\
\hline Falha no Molde & $q$-Weibull & 1,2527 & 3,1797 & - & - & 1,6545 & 0,98200 & 1 \\
\hline $\begin{array}{c}\text { Falhas não } \\
\text { determinadas } \\
\text { ou esporádicas }\end{array}$ & $q$-Weibull & 1,4738 & 25,888 & - & - & 1,2804 & 0,98248 & 1 \\
\hline Falha no Filtro & Weibull & 0,76025 & 158,86 & - & - & - & 0,94270 & 2 \\
\hline Falha no Molde & $q$-Weibull & 1,5698 & 39,000 & - & - & 1,4706 & 0,97067 & 2 \\
\hline $\begin{array}{l}\text { Falha na } \\
\text { Tréfila }\end{array}$ & $q$-Weibull & 0,87425 & 16,155 & - & - & 1,5108 & 0,98310 & 2 \\
\hline $\begin{array}{l}\text { Falha na Faca } \\
\text { de corte }\end{array}$ & Lognormal & - & - & 3,7419 & 2,6415 & - & 0,93031 & 2 \\
\hline $\begin{array}{c}\text { Falhas não } \\
\text { determinadas } \\
\text { ou esporádicas }\end{array}$ & Lognormal & - & - & 1,3155 & 2,7687 & - & 0,99350 & 2 \\
\hline Falha no Filtro & Normal & - & - & 12,332 & 111,81 & - & 0,89960 & 3 \\
\hline Falha no Molde & Normal & - & - & 49,915 & 70,866 & - & 0,97888 & 3 \\
\hline $\begin{array}{l}\text { Falha na Faca } \\
\text { de corte }\end{array}$ & $q$-Weibull & 1,4834 & 1,5611 & - & - & 1,6661 & 0,99115 & 3 \\
\hline $\begin{array}{c}\text { Falhas não } \\
\text { determinadas } \\
\text { ou esporádicas }\end{array}$ & $q$-Weibull & 49,511 & 39,845 & - & - & 1,9658 & 0,91000 & 3 \\
\hline Falha no Filtro & Normal & - & - & 46,607 & 62,924 & - & 0,94673 & 4 \\
\hline $\begin{array}{c}\text { Falhas não } \\
\text { determinadas } \\
\text { ou esporádicas }\end{array}$ & $q$-Weibull & 2,5763 & 0,85449 & & - & 1,8535 & 0,97114 & 4 \\
\hline Falha no Filtro & $q$-Weibull & 1,2163 & 62,915 & & & 1,1835 & 0,99105 & 5 \\
\hline $\begin{array}{c}\text { Falhas não } \\
\text { determinadas } \\
\text { ou esporádicas }\end{array}$ & $q$-Weibull & 1,0320 & 35,269 & & & 1,1422 & 0,98730 & 5 \\
\hline
\end{tabular}

Fonte: Próprio autor

Revista Produção Online, Florianópolis, SC, v.15, n. 1, p. 345-374, jan./mar. 2015. 
Figura 10 - Ajuste das distribuições propostas pela CLD: (a) máquina 1; (b) máquina 2; (c) máquina 3; (d) máquina 4; (e) máquina 5
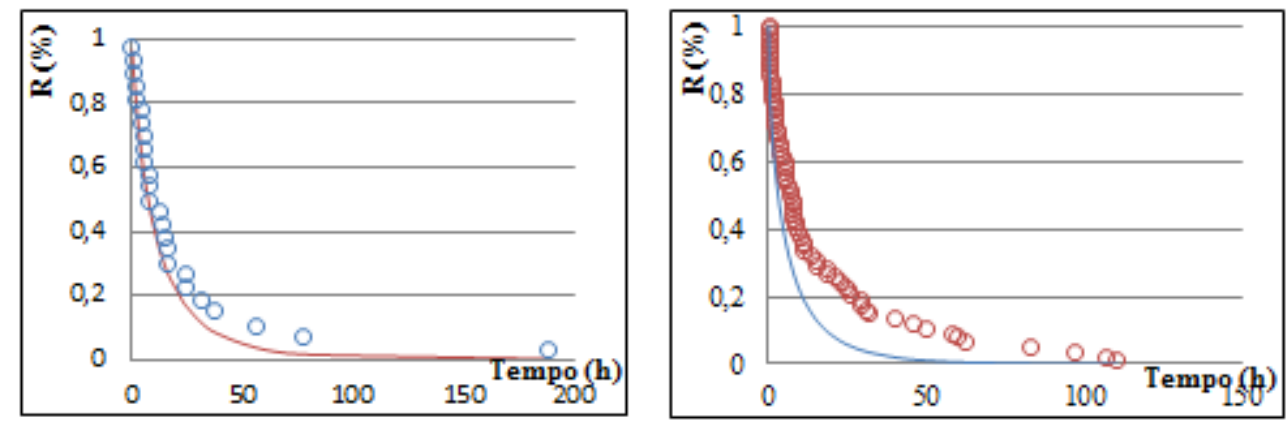

(a)

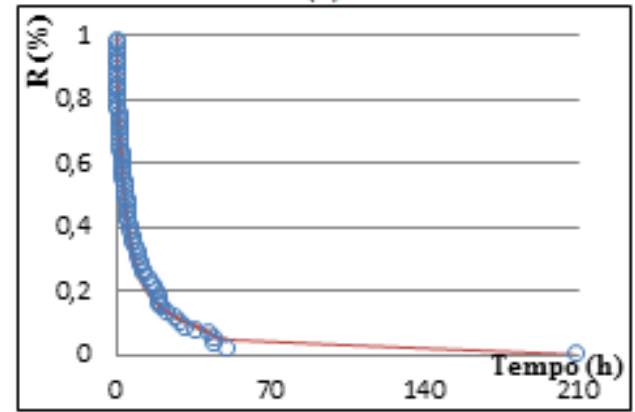

(c)

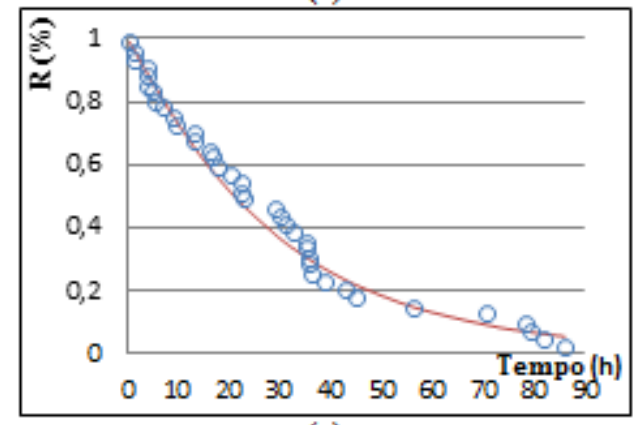

(b)

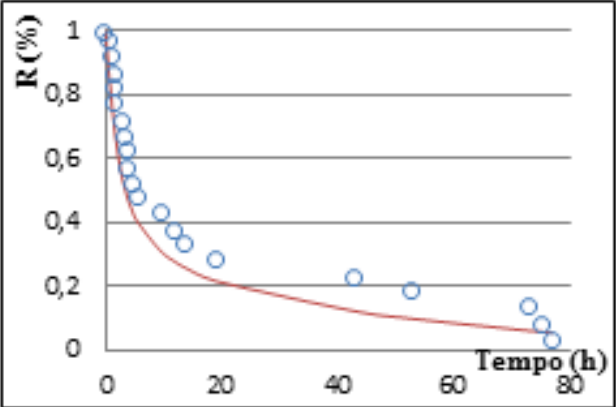

(d)

Dados Reais CLD

Fonte: Próprio autor

Como podem ser observados na Tabela 4, os resultados obtidos com a aplicação das expressões obtidas pela modelagem CLD não foram capazes de representar bem os dados de todas as máquinas. Apesar desta modelagem ser capaz de representar os subsistemas, ela nem sempre é capaz de representar bem os dados globais das máquinas, como pode ser visto especialmente nos modelos das máquinas 2 e 4.

Revista Produção Online, Florianópolis, SC, v.15, n. 1, p. 345-374, jan./mar. 2015. 
Tabela 4 - Coeficientes de determinação das representações obtidas com as expressões encontradas segundo a modelagem CLD

\begin{tabular}{cc}
\hline Máquina (M) & Coeficiente de determinação $\left(\mathbf{R}^{\mathbf{2}}\right)$ \\
\hline 1 & 0,93862 \\
2 & 0,65254 \\
3 & 0,95689 \\
4 & 0,85231 \\
5 & 0,98119 \\
\hline
\end{tabular}

Fonte: Próprio autor

\subsubsection{Otimização da Distribuição de Vida Composta (OCLD)}

Como mostrado nos resultados anteriores, a modelagem GLD é capaz de representar bem os dados globais de falha, mas não é capaz de representar os subsistemas. A abordagem CLD é capaz de descrever bem os subsistemas, mas muitas vezes resulta em uma descrição ruim dos dados globais de falha. A modelagem proposta pela OCLD é uma tentativa de encontrar um ajuste que possua, simultaneamente, uma boa representatividade para os subsistemas e também uma melhor representatividade do sistema como um todo.

O modelo encontrado pela abordagem CLD é utilizado como estrutura de modelo para re-estimar os parâmetros utilizando os dados globais do sistema. Aplicando tal procedimento são obtidos os resultados mostrados na Tabela 5 e na Figura 11.

Revista Produção Online, Florianópolis, SC, v.15, n. 1, p. 345-374, jan./mar. 2015. 
Tabela 5 - Re-estimativa proposta pela modelagem OCLD

\begin{tabular}{|c|c|c|c|c|c|c|c|}
\hline Modo de Falha & Distribuição & $\begin{array}{c}\text { Parâmetro } \\
\text { de forma }(\beta)\end{array}$ & 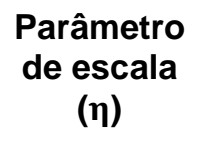 & $\begin{array}{c}\text { Desvio } \\
\text { padrão }(\sigma)\end{array}$ & $\begin{array}{l}\text { Média } \\
(\mu)\end{array}$ & $\begin{array}{l}\text { Parâmetro } \\
\text { "q" }\end{array}$ & $\mathbf{M}$ \\
\hline Falha no Molde & $q$-Weibull & 1,4942 & 0,49633 & - & - & 1,9470 & 1 \\
\hline $\begin{array}{c}\text { Falhas não } \\
\text { determinadas } \\
\text { ou esporádicas }\end{array}$ & $q$-Weibull & 1,7235 & 7,7433 & - & - & 1,6063 & 1 \\
\hline Falha no Filtro & $q$-Weibull & 0,82145 & 158,29 & - & - & 1,1397 & 2 \\
\hline Falha no Molde & $q$-Weibull & 2,0366 & 44,479 & - & - & 1,9904 & 2 \\
\hline Falha na Tréfila & $q$-Weibull & 0,98301 & 4,6950E-08 & - & - & 2,0000 & 2 \\
\hline $\begin{array}{c}\text { Falha na Faca } \\
\text { de corte }\end{array}$ & Lognormal & - & - & 1,9686 & 2,3447 & - & 2 \\
\hline $\begin{array}{c}\text { Falhas não } \\
\text { determinadas } \\
\text { ou esporádicas }\end{array}$ & Lognormal & - & - & 1,4406 & 3,9273 & - & 2 \\
\hline Falha no Filtro & Normal & - & - & 14,491 & 138,20 & - & 3 \\
\hline Falha no Molde & Normal & - & - & 30,753 & 85,283 & - & 3 \\
\hline $\begin{array}{c}\text { Falha na Faca } \\
\text { de corte }\end{array}$ & $q$-Weibull & 1,6231 & 1,5326 & - & - & 1,6979 & 3 \\
\hline $\begin{array}{c}\text { Falhas não } \\
\text { determinadas } \\
\text { ou esporádicas }\end{array}$ & $q$-Weibull & 47,603 & 16,421 & - & - & 1,9854 & 3 \\
\hline Falha no Filtro & Normal & - & - & 31,062 & 75,171 & - & 4 \\
\hline $\begin{array}{c}\text { Falhas não } \\
\text { determinadas } \\
\text { ou esporádicas }\end{array}$ & $q$-Weibull & 2,3522 & 1,0962 & - & - & 1,8499 & 4 \\
\hline Falha no Filtro & $q$-Weibull & 4,3638 & 28,215 & - & - & 1,7518 & 5 \\
\hline $\begin{array}{c}\text { Falhas não } \\
\text { determinadas } \\
\text { ou esporádicas }\end{array}$ & Weibull & 0,75898 & 49,442 & - & - & - & 5 \\
\hline
\end{tabular}

Fonte: Próprio autor

Revista Produção Online, Florianópolis, SC, v.15, n. 1, p. 345-374, jan./mar. 2015. 
Figura 11 - Ajuste das distribuições propostas pela OCLD par cada equipamento: (a) máquina 1; (b) máquina 2; (c) máquina 3; (d) máquina 4; (5) máquina 5

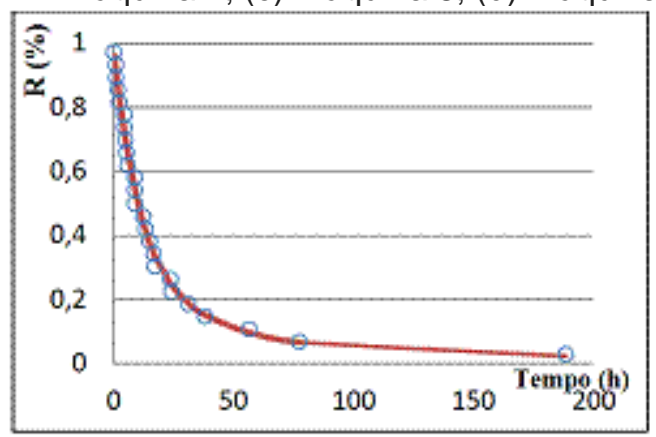

(a)

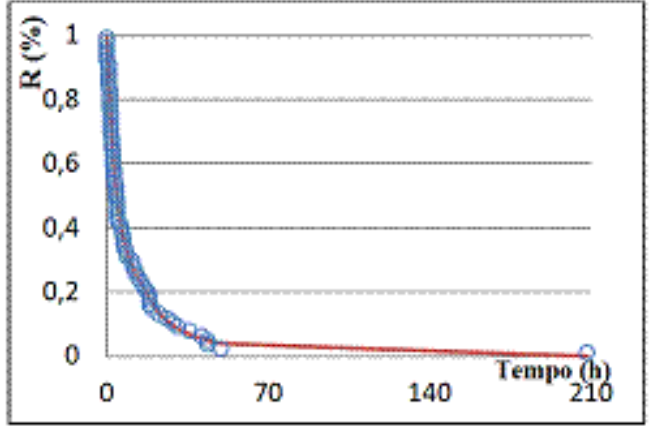

(c)

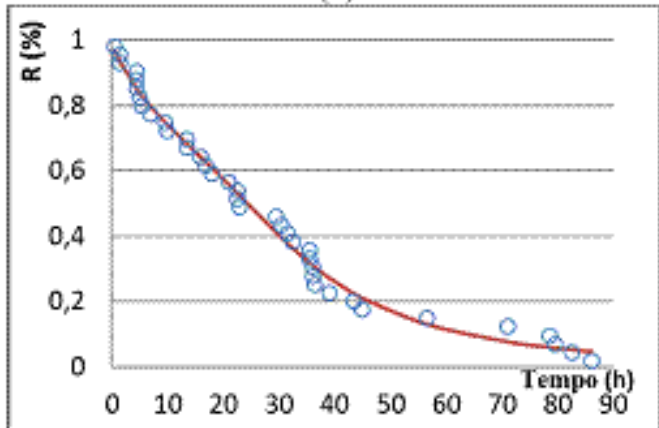

(e)

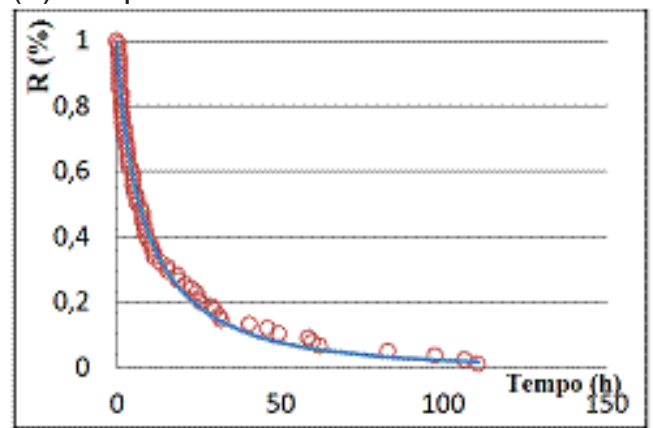

(b)

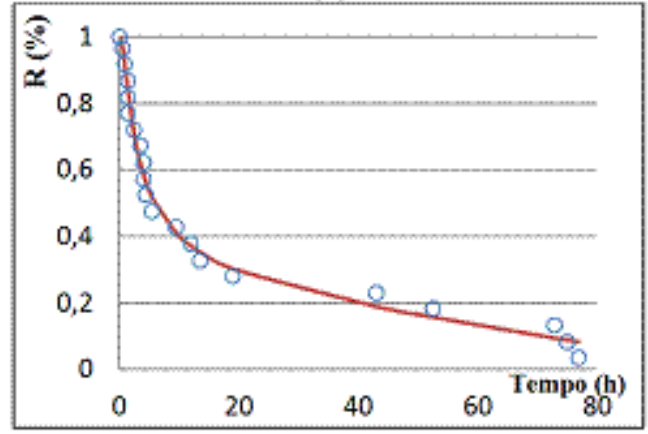

(d)

Fonte: Próprio autor

Apesar de utilizar a mesma estrutura de modelo obtida pela modelagem CLD, a OCLD resultou em uma melhor representação, como pode ser constatado pelos elevados valores do coeficiente de determinação $\left(R^{2}\right)$ mostrados na Tabela 6.

Revista Produção Online, Florianópolis, SC, v.15, n. 1, p. 345-374, jan./mar. 2015. 
Tabela 6 - Coeficientes de determinação das representações obtidas com as expressões encontradas segundo a modelagem OCLD

\begin{tabular}{cc}
\hline Máquina (M) & Coeficiente de determinação $\left.\mathbf{( R}^{\mathbf{2}}\right)$ \\
\hline 1 & 0,99446 \\
2 & 0,99201 \\
3 & 0,99686 \\
4 & 0,98741 \\
5 & 0,99088 \\
\hline
\end{tabular}

Fonte: Próprio autor

\subsection{Análises e Comparações Complementares}

Uma das formas mais utilizadas por profissionais da área de confiabilidade para encontrar uma expressão para a confiabilidade de sistemas é a GLD-exponencial. Esta modelagem é bem simples e consiste na realização de um ajuste GLD considerando apenas a distribuição exponencial, cujos resultados obtidos para o caso sob análise podem ser encontrados na Tabela 7 , comparados às demais abordagens utilizadas nas seções anteriores.

Tabela 7 - Comparação dos métodos de modelagem

\begin{tabular}{|c|c|c|c|c|}
\hline Máquina (M) & GLD-exponencial ( $\left.\mathbf{R}^{2}\right)$ & GLD $\left(R^{2}\right)$ & CLD $\left(R^{2}\right)$ & $\overline{O C L D}\left(R^{2}\right)$ \\
\hline 1 & 0,98177 & 0,99387 & 0,93862 & 0,99446 \\
\hline 2 & 0,94596 & 0,99529 & 0,65254 & 0,99201 \\
\hline 3 & 0,96368 & 0,99520 & 0,95689 & 0,99686 \\
\hline 4 & 0,88624 & 0,98242 & 0,85231 & 0,98741 \\
\hline 5 & 0,98453 & 0,98584 & 0,98119 & 0,99088 \\
\hline
\end{tabular}

Fonte: Próprio autor

As modelagens GLD-exponencial e CLD resultaram em coeficientes de determinação abaixo de 0,98 para a maioria dos casos (máquinas 2, 3 e 4, no caso da GLD-exponencial, e máquinas 1, 2, 3 e 4, no caso da CLD). Como também pode ser observado na Tabela 7 através dos elevados valores dos coeficientes de determinação, a GLD e a OCLD resultaram em boa representação do comportamento da Revista Produção Online, Florianópolis, SC, v.15, n. 1, p. 345-374, jan./mar. 2015. 
confiabilidade dos dados globais em todos os casos. A OCLD, além da vantagem de descrever o comportamento de cada subsistema, se destacou por ser a melhor metodologia em todos os casos, com exceção da máquina 2, cuja modelagem proposta pela GLD resultou em um $\mathrm{R}^{2}$ maior. As expressões que melhor representam cada equipamento podem ser observadas na Tabela 8.

Tabela 8 - Expressões que melhor representam a confiabilidade de cada equipamento

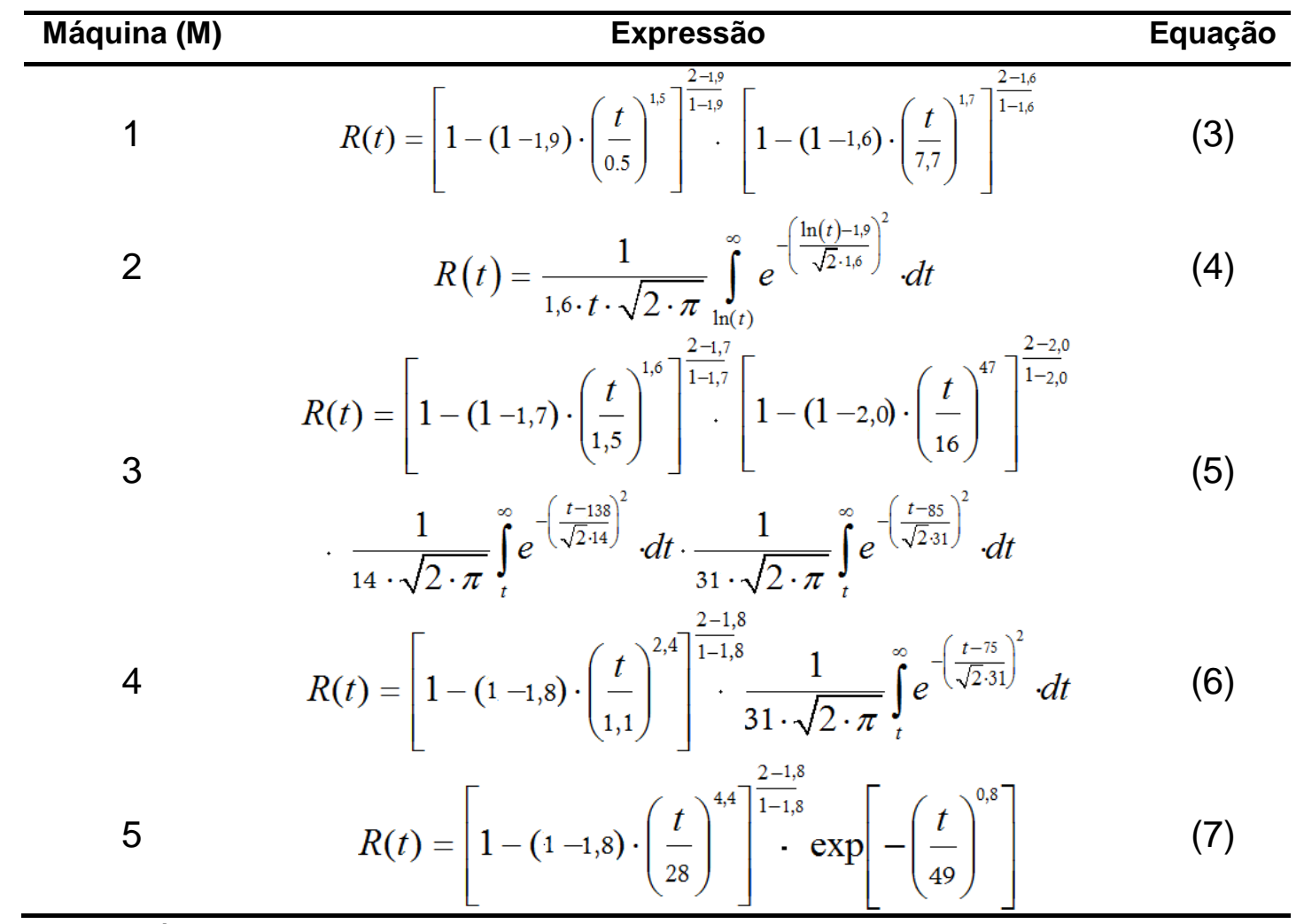

Fonte: Próprio autor

A Figura12 mostra o comportamento da confiabilidade dos equipamentos calculada pelos métodos paramétricos aqui empregados (incluindo aqueles da Tabela 8), comparando-o aos dados reais. Em relação à máquina 1, observa-se que as modelagens OCLD e GLD resultaram em uma boa representação do comportamento dos dados reais. Por outro lado, a modelagem CLD começa a sofrer distorções a partir de aproximadamente 5,5 horas, sendo capaz de representar bem cerca de $36 \%$ dos dados. A modelagem exponencial é fiel ao comportamento dos dados até o tempo em Revista Produção Online, Florianópolis, SC, v.15, n. 1, p. 345-374, jan./mar. 2015. 
torno de 17 horas, e é capaz de representar bem aproximadamente $68 \%$ dos dados. As modelagens OCLD e GLD também resultaram em uma boa representação para as máquinas 2 e 3 . A modelagem CLD, por sua vez, embora tenha conseguido acompanhar bem o comportamento da máquina 3 , não conseguiu representar adequadamente o comportamento da máquina dois em nenhum período. A modelagem exponencial sofreu distorções para os dados de ambas as máquinas, representando bem os dados até os tempos de 11,5 horas para a máquina 2 e de 9 horas para a 3 , resultando, respectivamente, em cerca de $67 \%$ e $73 \%$ de dados bem representados. A máquina 5 foi a única para a qual todas as modelagens conseguiram representar bem o comportamento da confiabilidade, apenas com pequenas distorções na cauda das distribuições. A máquina 4 não foi bem representada pela modelagem CLD, mesmo nos primeiros instantes, nem pela modelagem exponencial, neste caso a partir de 1,5 horas, que só conseguiu representar bem cerca de $15 \%$ dos dados analisados.

Todos os métodos de modelagem, com exceção da CLD, foram capazes de representar o comportamento da confiabilidade das máquinas para pequenos períodos de tempo. Já quando analisados os períodos de tempo maiores, a GLD-exponencial começa a sofrer desvios. Apenas as abordagens OCLD e GLD não sofreram grandes distorções nos casos estudados, com exceção das máquinas 4 e 5, para as quais todas as modelagens sofreram distorções nos períodos finais. É importante ressaltar que há uma maior concentração de dados nos períodos iniciais, o que justifica uma representação melhor nestes períodos.

Revista Produção Online, Florianópolis, SC, v.15, n. 1, p. 345-374, jan./mar. 2015. 
Figura 12 - Ajuste das modelagens GLD, GLD-exponencial, CLD e OCLD para os equipamentos: (a) máquina 1; (b) máquina 2; (c) máquina 3; (d) máquina 4; (e) máquina 5
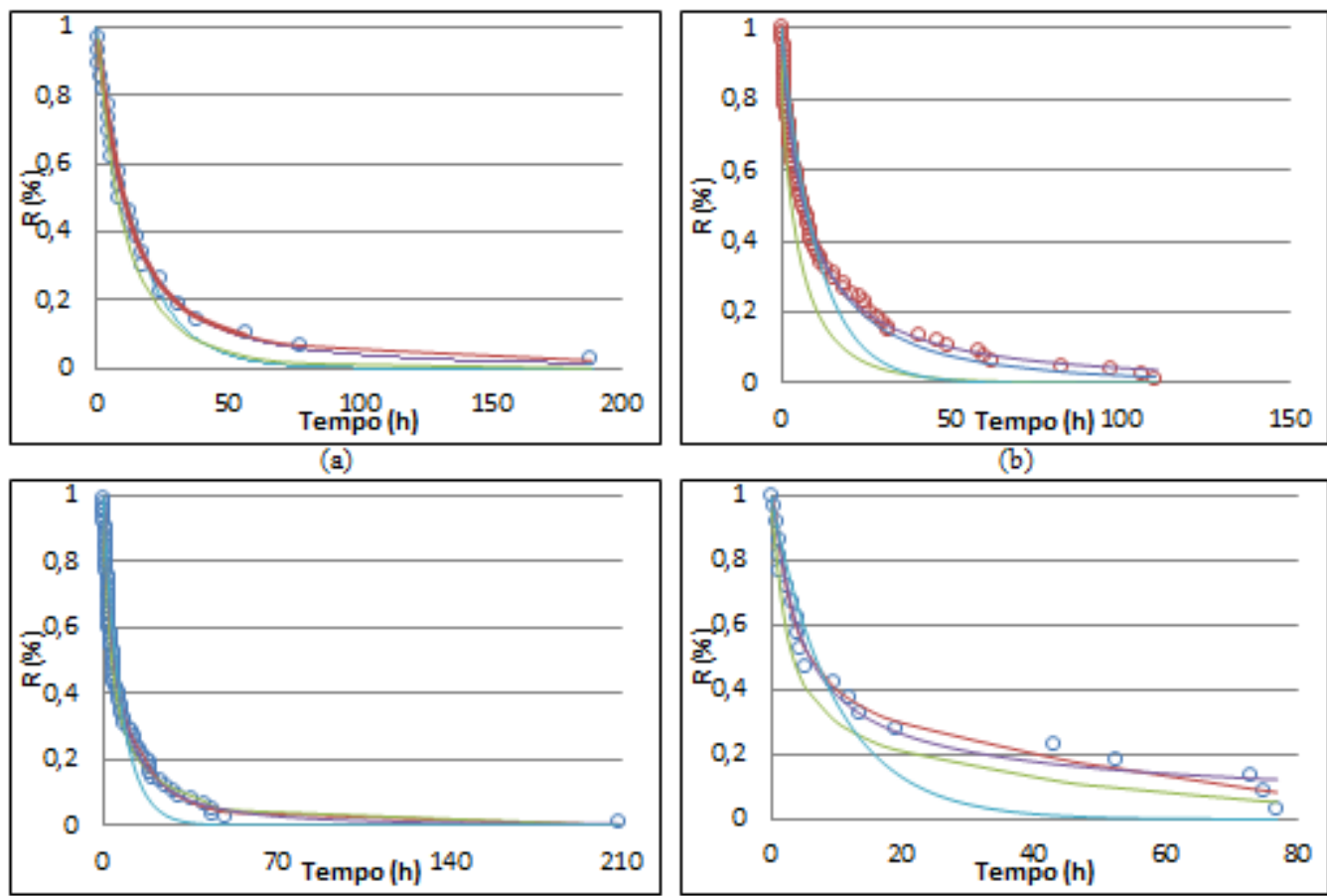

(c)
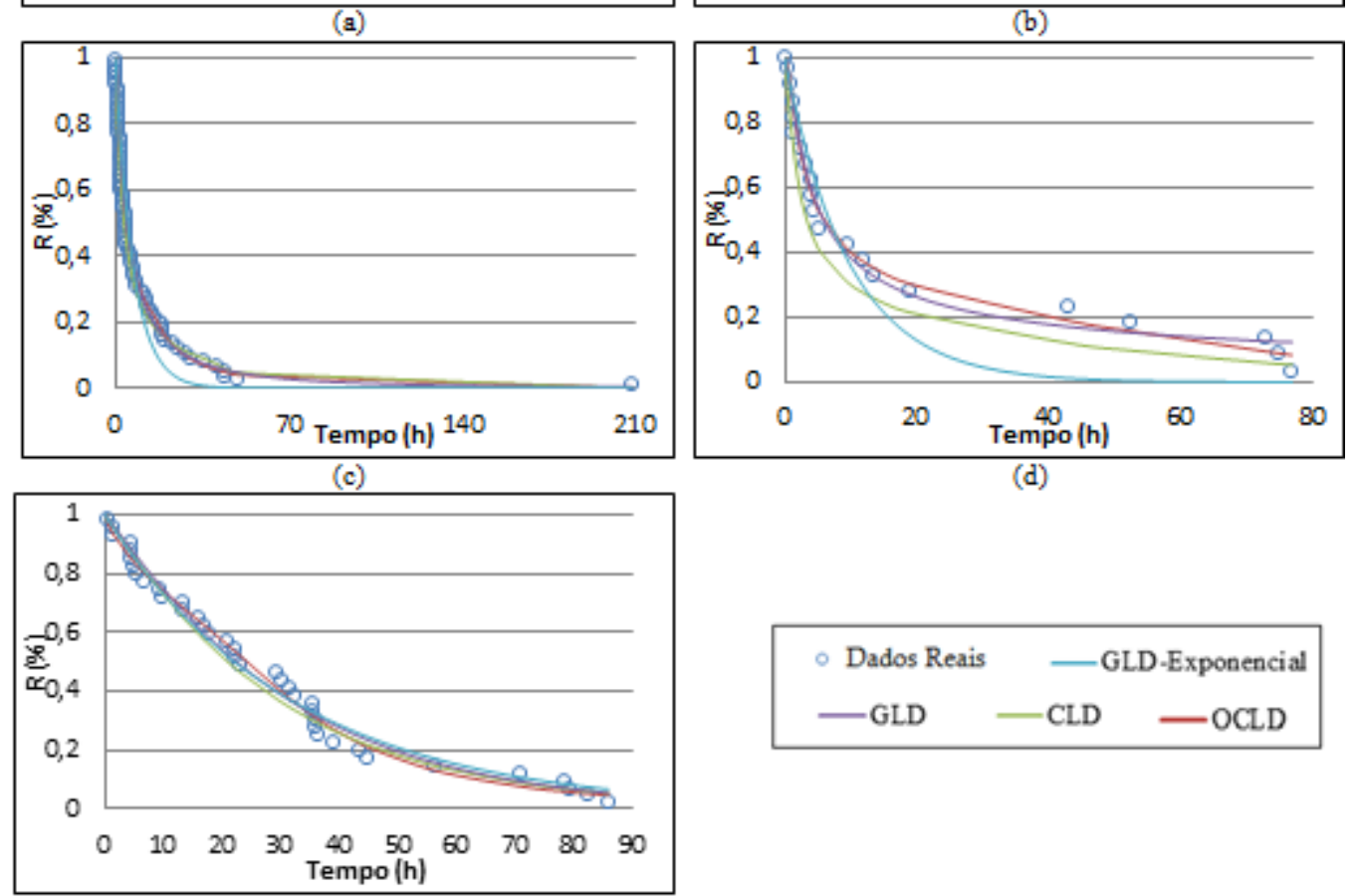

(d)

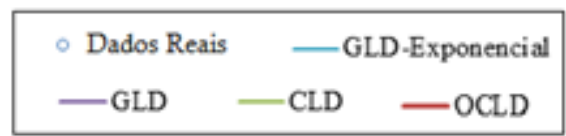

Fonte: Próprio autor

\section{CONCLUSÃO}

Neste trabalho foi estudado e analisado o comportamento da confiabilidade de uma unidade industrial de saneantes através das abordagens de modelagem GLD, CLD e OCLD aplicadas aos dados de parada da produção de frascos, utilizando tanto distribuições clássicas quanto generalizadas: exponencial; Weibull; lognormal; normal; $q$-exponencial; $q$-Weibull. Tomando os valores do coeficiente de determinação $\left(\mathrm{R}^{2}\right)$

Revista Produção Online, Florianópolis, SC, v.15, n. 1, p. 345-374, jan./mar. 2015. 
como base de comparação, a abordagem OCLD, dentre aquelas empregadas, é a que melhor representa os dados das máquinas, tanto para o sistema global quanto para seus subsistemas. Embora a abordagem GLD consiga uma boa descrição global do sistema, ela não é capaz de fornecer a descrição dos seus subsistemas. Além disso, em sua forma mais popularmente utilizada no âmbito industrial, a GLD-exponencial, a representação pode não ser boa mesmo na descrição dos dados globais de falha. $A$ abordagem CLD, por outro lado, apesar de fornecer a descrição dos subsistemas, apresenta resultados muitas vezes ruins na descrição do sistema global. O maior sucesso da metodologia OCLD pode ser explicado pelo fato dela reter as boas características das metodologias GLD e CLD, mas transpor as suas limitações, pois representa bem simultaneamente os comportamentos do sistema global e dos seus subsistemas. O lucro cessante também foi estimado, chegando-se a um valor da ordem de $\mathrm{R} \$ 323.400,00$ anuais, o que é um indicador do potencial financeiro que pode ser obtido com investimentos na área de confiabilidade.

Foi ainda efetuada a análise de contribuição das falhas em filtro, tréfila, molde, faca de corte e das não determinadas ou esporádicas para a probabilidade de falha do sistema global. Este estudo revelou que, de forma geral, os modos de falha mais importantes são falhas no molde e no filtro, e ele pode ser utilizado como uma ferramenta para tomada de decisões específicas.

\section{AGRADECIMENTOS}

Os autores agradecem à Como Limpa Ltda. pelo apoio técnico e ao CNPq pelo apoio financeiro.

\section{REFERÊNCIAS}

ABIPLA - ASSOCIAÇÃO BRASILEIRA DAS INDÚSTRIAS DE PRODUTOS DE LIMPEZA E AFINS. Anuário da ABIPLA 2011. ABIPLA, 6. ed. São Paulo, 2011. 
ALCÂNTARA, M. L. Modelagem ótima da confiabilidade de uma unidade industrial de produção de saneantes. Trabalho Final de Curso - Curso de Graduação em Engenharia Química, Universidade Federal da Bahia, Salvador, 2013.

BIROLINI, A. Reliability engineering: theory and practice. Springer, $3^{\mathrm{a}}$ ed. Berlin, Alemanha, 493p., 1999.

CASTET, J. F., SALEH, J. H., Satellite and satellite subsystems reliability: Statistical data analysis and modeling, Reliability Engineering and System Safety, v. 94, 1718-1728, 2009. http://dx.doi.org/10.1016/i.ress.2009.05.004

CROOKSTON, K. A., YOUNG, T. M., HARPER, D, GUESS, F. M. Statistical reliability analyses of two wood plastic composite extrusion process. Reliability Engineering and System Safety, v. 96, p. 172-177, 2011. http://dx.doi.org/10.1016/j.ress.2010.08.005

EUROMONITOR. Home Care. Euromonitor International, Londres, Inglaterra, 2011.

IBGE - Instituto Brasileiro de Geografia e Estatística. Comunicado Social 2011. IBGE, Rio de Janeiro, Brasil, 2011.

JOHNSON, L. G. The median ranks of sample values in their population with an application to certain fatigue studies. Bulletin of the American Mathematical Society, v. 56, p. 247-247, 1950.

LOPES, L. F. D., SAMOHYL, R. W. Análise de Componentes Principais: técnica alternativa de análise de confiabilidade em sistemas complexos multivariados. Produção Online, v. 3, p. 620658, 2003. http://dx.doi.org/10.14488/1676-1901.v3i2.620

MENGUE, D. C., SELLITTO, M. A. Estratégia de manutenção baseada em funções de confiabilidade para uma bomba centrífuga petrolífera, Produção Online, v. 13, p. 759-783, 2013. http://dx.doi.org/10.14488/1676-1901.v13i2.1341

NADARAJAH, S., KOTZ, S. On the q-typedistribution, Physica A, v. 377, p. 465-468, 2007. http://dx.doi.org/10.1016/j.physa.2006.11.054

PICOLI, J. S., MENDES, R. S., MALACARNE, L. C., SANTOS, R. P. B., q-distributions in complex systems: a brief review. Brazilian Journal of Physics, v. 39, p. 68-474, 2009. http://dx.doi.org/10.1590/S0103-97332009000400023

RAUSAND, M. A. System reliability theory: models, statistical methods, and applications. Wiley-Interscience, $2^{\mathrm{a}}$ ed. New Jersey, Estados Unidos da América, 664p, 2004.

SALEM, A., SENE, R. A. Optimization of zeolite-based adsorvent composition for fabricating reliable Raschig ring shaped by extrusion using Weibull statical theory. Microporous and Mesoporous Materials, v. 163, p. 65-75, 2012. http://dx.doi.org/10.1016/j.micromeso.2012.06.026 
SARTORI, I. Uma abordagem de desenvolvimento de sistemas de detecção e diagnóstico de falhas baseada em estudos prévios de confiabilidade e sua aplicação ao processamento industrial de gás natural. Salvador: UFBA, 2013. 242 p. Tese (Doutorado) Programa de Pós-Graduação em Engenharia Industrial, Escola Politécnica, Universidade Federal da Bahia, Salvador, 2013.

SHEIKH, A. K., ARIF, A. F. M., QAMAR, S. Z. A probabilistic study of failures of solid and hollow dies in hot aluminum extrusion. Journal of Materials Processing Technology, v. 155-156, p. 1740-1748, 2004. http://dx.doi.org/10.1016/j.jmatprotec.2004.04.170

TSALLIS, C. Possible generalization of boltzmann-gibbs statistics. Journal of Statistical Physics, v. 52, p. 479-487, 1988. http://dx.doi.org/10.1007/BF01016429

YOUNAS, M. SHEIKH, A. K., ARIF, A. F. M. Impact of repeated nitriding cycles on extrusion die life - some statistical and metallurgical observations. Journal of Failure Analysis and Prevention, v. 8, p. 461-468, 2008. http://dx.doi.org/10.1007/s11668-008-9154-5

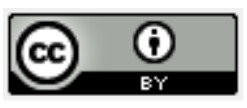

Artigo recebido em 11/09/2014 e aceito para publicação em 12/11/2014 DOI: $\underline{\text { http://dx.doi.org/ 10.14488/1676-1901.v15i1.1882 }}$

Revista Produção Online, Florianópolis, SC, v.15, n. 1, p. 345-374, jan./mar. 2015. 